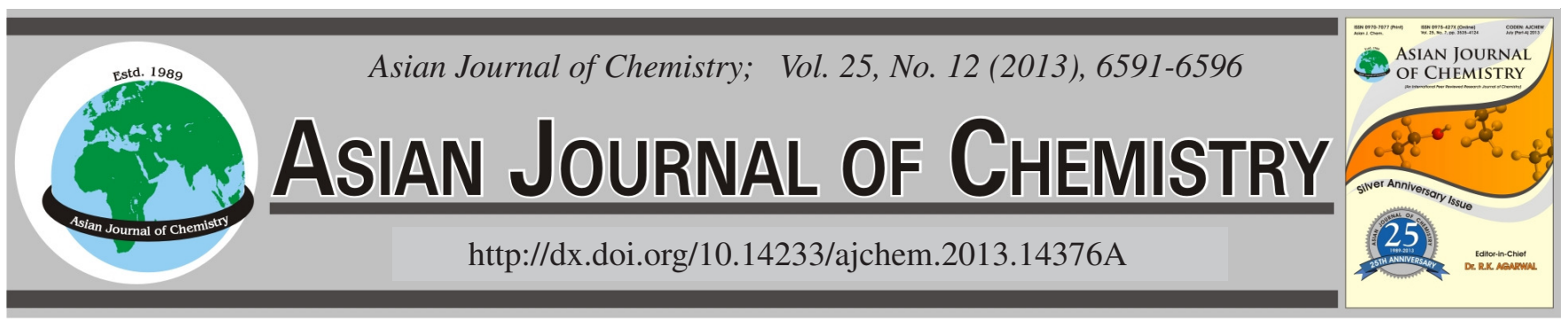

\title{
Anti-Diabetic and Anti-Oxidant Activity of Leaf and Bark Extracts of Murraya koenigii on Streptozotocine Induced Diabetic Rats
}

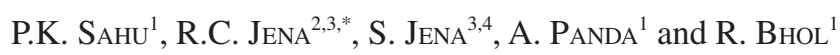

${ }^{1}$ Department of Biotechnology, Rama Devi (Auto) Women's College, Bhubaneswar-751 022, India

${ }^{2}$ DNA Fingerprinting Laboratory, Biotechnology-Cum-Commercial Tissue Culture Centre, Orissa University of Agriculture and Technology, Bhubaneswar-751 003, India

${ }^{3}$ Post Graduate Department of Botany, Utkal University, Bhubaneswar-751 004, India

${ }^{4}$ University Department of Pharmaceutical Sciences, Utkal University, Bhubaneswar-751 004, India

*Corresponding author: E-mail: jena_ramchandra@yahoo.co.in; jena_ramachandra@rediffmail.com

(Received: 31 July 2012;

Accepted: 22 May 2013)

AJC-13528

\begin{abstract}
The anti-hyperglycemic and anti-oxidant activity of leaves and bark extracts (aqueous, methanolic, chloroform and $n$-hexane) of $M u r r a y a$ koenigii was evaluated on streptozotocin induced diabetic in wistar albino rats. The leaf and bark extract was demonstrated $\mathrm{LD}_{50}>3 \mathrm{~g} / \mathrm{kg}$ and $\mathrm{LD}_{50}>3.6 \mathrm{~g} / \mathrm{kg}$ respectively with low toxicity. Remarkable loss body weight retrieval $(+14.37 \mathrm{~g})$ was demonstrated by using Murraya koenigii leaf aqueous extract. Among all the different polarity of leaf and bark extracts, the aqueous and methanolic leaf extract at the dose levels of $300 \mathrm{mg} / \mathrm{kg}$ body weight produced a significant decrease in fasting blood glucose level by 64.16 and $60.84 \%$ respectively with respect to initial fasting blood glucose level after 15 days of the treatment. In the oral glucose tolerance test, the aqueous and methanolic leaf extracts at the dose levels of $300 \mathrm{mg} / \mathrm{kg}$ was also effective that decreased glycemia $(2.7 \%$ and $2.1 \%)$ at $1 \mathrm{~h}$ and the effect persisted unit at $2 \mathrm{~h} .(\mathrm{p}<0.05)$ after glucose loading, which revealed impaired glucose tolerance. Aqueous leaf extract demonstrated highest DPPH free radical scavenging activity at $89.32 \pm 1.65$ than the methanolic, chloroform and $n$-hexane extracts $76.34 \pm 1.56,67.89 \pm 1.54$ and $59.56 \pm 1.32$ respectively at a concentration of $100 \mu \mathrm{g} / \mathrm{mL}$. Beside this aqueous leaves extract also revealed highest Ferric-reducing antioxidant power assay value i.e. $76.32 \pm 1.87$ than the other extracts at a concentration of $100 \mu \mathrm{g} / \mathrm{mL}$. For all the estimated parameters used with leaf and bark the results of the aqueous leaf extract treated groups were restored to the near normal level, there by indicating good anti-hyperglycemic activity of the leaf aqueous extract of Murraya koenigii.
\end{abstract}

Key Words: Murraya koenigii, Anti-hyperglycemic, Hypoglycemic, Diabetes mellitus, Streptozotocin, Antioxidant.

\section{INTRODUCTION}

Diabetes mellitus, an endocrine disorder, characterized by hyperglycemia and affects a large number of people worldwide. The largest chronic metabolic disorder disease of the world, the diabetes, is almost all in a devastating form with presently over 150 million patients ${ }^{1}$, which has become now a life style problem. The demographic study, estimated that by 2025 the earth will have more than 300 million peoples with this invasive disorder of endocrine disease and India being with around 60 million followed by Chinese and USA ${ }^{2,3}$. In modern medicine, no satisfactory effective therapy is still available to cure diabetes mellitus ${ }^{4}$. Various types of hypoglycemic agents like glibenclamide, beguanides and sulfonureas and synthetic insulin etc, meant for diabetic treatment, but its long term use have some side effect due to its toxicity (PK3456) and even these are not advisable to be safe during pregnancy. Currently available therapeutic options such as dietary modi- fication, oral hypoglycemic and insulin have limitations of their own in treating non-insulin dependent diabetes mellitus ${ }^{5,6}$. Therefore, the search for more effective and safer hypoglycemic agents has continued to be an area of active research. The world health organization has recommended the evaluation of the effectiveness of medicinal plants in condition where the conventional allopathic treatment of diabetes is not adequate ${ }^{7,8}$. Medicinal plants are gifts of God, to cure infinite number of diseases among the human beings and in other living organism ${ }^{9}$. The phytochemicals identified from traditional medicinal plants are presenting an exciting opportunity for the development of new types of therapeutics ${ }^{10}$. Many ethno botanical surveys on medicinal plants used by the local population have been performed in different parts of the world including India ${ }^{11-13}$. In ancient literature there have been medicine and plant that has been used in tradition medicines for their antidiabetic properties without any scientific support and pharmaceutical evidence. Many herbs and plants have been described 
as possessing hypoglycemic activity when taken orally ${ }^{14,15}$. India throughout its long history has accumulated a rich body of experimental facts of the use of medicinal plants for the treatment of various diseases. Chemical studies of Indian medicinal plants offered a valuable material base for the discovery and development of new drugs of natural Origin. Systematic screening of them may result in the discovery of novel effective compounds ${ }^{16}$. The abundance of plants on the earth's surfaces has led to an increasing interest in the investigation of different extracts obtained from traditional medicinal plants as potential sources of new anti-oxidant agents. Contrary to the synthetic drugs, antioxidents of plant origin are not associated with many side effects and have an enormous therapeutic potential to heal many metabolic diseases. Many efforts have been made to ascertain new antioxidant and anti-diabetic properties from plants and recently several workers have reported the anti-oxidant and anti-diabetic activities occurring medicinal plants ${ }^{17-20}$

Plants have been the major source of drugs for the treatment of diabetes mellitus in Indian medicine and other ancient systems in the world and for a long time diabetes mellitus has been treated orally with herbal medicines or their extracts $^{21}$, because plant products are frequently considered to be less toxic and more free from side effects than synthetic ones ${ }^{14}$. Furthermore, after the recommendations made by the WHO on DMO on diabetes mellitus, investigations on hypoglycemic agents from medicinal plants have become more important and the search for more effective and safer hypoglycemic agents has continued to be an important area of active research. Surveys conducted in Australia and US indicate that almost 48.5 and $34 \%$ of respondents had used at least one form of unconventional therapy including herbal medicine ${ }^{22,23}$. Indian figures are not available. The World Health Organization (1980) has also recommended the evaluation of the effectiveness of plants in conditions where we lack safe modern $\operatorname{drugs}^{8}$. Consequently researchers are focusing their attention more and more to herbal medicine pursue for new direction to develop superior drugs against microbial infection. This revival of interest in plant derived drugs is mainly due to current wide spread belief that herbal medicines is safe and more trustworthy and steady than expensive synthetic drugs, which may have adverse side effects. It is also reported adherence of green leafy vegetables is inversely associated with the risk of type 2 diabetes in large Indian population ${ }^{24}$.

In the indigenous Indian system of medicine (Ayurveda), many herbal medicines have been recommended for the treatment of 'madhumeha' or 'diabetes' and some of them have been pharmacologically evaluated and shown to be of some value in human diabetes treatment. Murraya koenigii is a highly aromatic small tree, commonly known as 'curry tree' belongs to family Rutaceae, order sapindales. The leaves of this plant although most commonly used in curries but also used as an herb in Ayurvedic medicine. The plant contain several Photochemical being credited with antitoxic, stomachic, carminative, anti-diabetic ${ }^{25}$, anti-oxidant ${ }^{26}$, anti-cancer, anti-microbial, antiinflammatory, hepatoprotective, anti-hypercholesterolemic, etc. The undiluted essential oil exhibited strong antibacterial, anti-fungal activity ${ }^{27}$, even crude leaf extract reported for anti- bacterial activity. Ayurveda mentioned its use as treatment for diabetes ${ }^{13}$. Hypoglycemic action on carbohydrate metabolism in rats feed leaves extract. The aqueous and methanol leaf extract of the plant has been studied for its anti-diabetic effect in alloxan-induced diabetic rats $^{28}$. So the present study was conducted to investigate the effect of anti-oxidant and aqueous, methanol, chloform and $n$-hexane extracts of Murraya koenigii leaves and barks on the levels of blood glucose and plasma insulin on streptozotocin induced diabetic in wistar albino rats with a view to ascertain scientific evidence in modern line.

\section{EXPERIMENTAL}

The leaves and barks of Murraya koenigii were collected from Bhubaneswar, India, during the month of November 2011.The plant was identified by Dr. K.B. Jena, Ayush Medical Officer, Jaleswarpur C.H.C., Balasore, India. A voucher specimen was submitted in the P.G. Department of Botany, Utkal University, Bhubaneswar, India for future reference.

Preparation of plant extracts: Freshly collected plant parts (leaf and bark) were washed under running tap water, dried under shade and powdered with the help of mechanical grinder. The powder was first defatted with petroleum ether $\left(40-60{ }^{\circ} \mathrm{C}\right.$ ) followed by extraction with $n$-hexane, chloroform, methanol and water in Soxhlet apparatus for $48 \mathrm{~h}$. The leaf and bark extracts were filtered separately and concentrated under vacuum. The yield of $n$-hexane, chloroform, methanol and aqueous leaf and bark extracts were 4, 3, 5, 5, 5, 4,10 and $7 \mathrm{~g} \mathrm{w} / \mathrm{w}$ respectively with respect to the dried powdered plant material. The methanolic and aqueous extracts were then separately suspended in Tween-80 (5\% v/v) and screened for antihyperglycemic activity.

Animals: The wistar albino rats (150-200 g) and swice albino mice (20-25 g) of both sexes were procured from Orissa University of Agriculture and Technology, Bhubaneswar, India and kept in the animal house of University Department of Pharmaceutical Sciences, Utkal University, Bhubaneswar, India. They had free access to standard food and water and maintained under standard condition at a temperature of $25 \pm 2{ }^{\circ} \mathrm{C}$, with a 12/12 -light/dark cycle and 35-60\% humidity. The conditions in the animal house and the study protocols were approved by the committee for the purpose of control and supervision on experiments on animals of University Department of Pharmaceutical Sciences, Utkal University.

Acute toxicity study: The lethal dose $\left(\mathrm{LD}_{50}\right)$ of the extracts was assessed by using swice albino mice of either sex weighing about 20-25 g. The animals were fasted overnight prior to the experimental procedures. Different doses of extracts were separately administered to the animals by the intra peritoneal route. The $\mathrm{LD}_{50}$ was calculated by following the method reported by Miller $\&$ Tainter $^{29}$ and Muhammad ${ }^{30} .1 / 10^{\text {th }}$ of the lethal dose was taken as the screening dose $\mathrm{e}^{31}$.

Study on glucose-loaded animals: The rats were kept fasting overnight with free access to water. The fasting blood glucose level of each animal was determined at the beginning of the experiment. The animals of control group received only the vehicle and the test groups were treated with the suspension of $n$-hexane, chloroform, methanolic and aqueous extracts of 
TABLE-1

EFFECTS OF DIFFERENT POLARITY OF LEAF AND BARK EXTRACT Murrya koengii on BODY WEIGHT

\begin{tabular}{lcccc}
\hline Groups & Initial weight $(\mathrm{g})$ & Final weight $(\mathrm{g})$ & Change in body & Change in body weight $(\%)$ \\
\hline Normal control & $160.00 \pm 8.91$ & $205.17 \pm 6.78$ & $45.17 \pm 6.78$ & +28.23 \\
Diabetic control & $172.00 \pm 8.42$ & $152.83 \pm 8.78$ & $-19.17 \pm 5.21$ & -11.15 \\
Diabetic + Glibenclamide & $170.00 \pm 7.89$ & $208.50 \pm 8.16$ & $38.50 \pm 5.98$ & +22.65 \\
Diabetic + MKLA & $182.17 \pm 7.45$ & $208.35 \pm 6.02$ & $26.18 \pm 6.21$ & +14.37 \\
Diabetic + MKLM & $190.13 \pm 8.75$ & $213.91 \pm 5.67$ & $23.78 \pm 5.81$ & +12.50 \\
Diabetic + MKLC & $178.87 \pm 7.75$ & $199.52 \pm 7.88$ & $20.65 \pm 5.83$ & +11.54 \\
Diabetic + MKLN & $171.83 \pm 733$ & $187.48 \pm 7.66$ & $15.65 \pm 8.88$ & +9.10 \\
Diabetic + MKBA & $173.84 \pm 7.75$ & $195.49 \pm 6.78$ & $21.65 \pm 8.90$ & +12.45 \\
Diabetic + MKBM & $190.83 \pm 6.65$ & $209.52 \pm 5.55$ & $18.69 \pm 8.78$ & +9.79 \\
Diabetic + MKBC & $180.81 \pm 672$ & $197.58 \pm 5.69$ & $16.77 \pm 8.88$ & +9.27 \\
Diabetic + MKBN & $185.81 \pm 6.83$ & $198.69 \pm 6.79$ & $12.88 \pm 9.99$ & +6.93 \\
\hline N.B: Results expressed as mean \pm SD $(\mathrm{n}=6)$, MKL: Murrya koengii leaf, MKB: Murrya koengii bark &
\end{tabular}

at dose levels of $300 \mathrm{mg} / \mathrm{kg} \mathrm{b}$. wt. Glibenclamide $(10 \mathrm{mg} / \mathrm{kg} \mathrm{b}$. wt.) was administered as the standard drug. Blood sugar levels were determined at $8,16,24 \mathrm{~h}$ and $10^{\text {th }}$ day after the oral administration of test samples to assess the effect of the test samples on normo-glycemic rats.

Induction of experimental diabetes: The wistar rats were kept fasting for $24 \mathrm{~h}$ and there after diabetes was induced by intraperitonial injection of streptozotocin, freshly dissolved in citrate buffer ( $\mathrm{pH} 4.5$ ) immediately before use. Streptozotocin was given at dose of $120 \mathrm{mg} / \mathrm{kg}$ of body weight. In order to avoid the streptozotocin induced hypoglycaemic mortality, $5 \%$ glucose solution was given for $24 \mathrm{~h}$ to streptozotocin treated rats. After $72 \mathrm{~h}$ of streptozotocin administration, the blood glucose levels were measured and the rats showing blood glucose level $>250 \mathrm{mg} / \mathrm{dl}$ were considered to be diabetic and were used for study. The rats were carefully monitored every day and weighed the normal control and experimental groups every week.

Study on streptozotocin induced diabetic rats: The rats were divided into different groups $(n=6)$. The treatment was made for 10 days. Control group received the vehicle $(2 \mathrm{~mL} /$ $\mathrm{kg}$ b. wt) and Glibenclamide (10 mg/kg b. wt) was given as the standard drug. The animals of the test groups received the, $n$-hexane, chloroform, methanol and aqueous leaf and bark extracts of Murraya koenigii at dose level of $300 \mathrm{mg} / \mathrm{kg} \mathrm{b}$. wt.

Testing of fasting blood glucose: The fasting blood glucose level of each animal was monitored on $0,8,16,24 \mathrm{~h}$ and 10 days. A drop of blood was collected from the tip of the tail vein of each rat and fasting blood glucose level was measured using Lever chek, TD-4230, Blood glucose monitoring system (Accureh Biomedical, Taiwan).

DPPH radical scavenging assay: The free radical scavenging activity of Murraya koenigii samples were measured using the 1,1-diphenyl-1-picryl-hydrazyl (DPPH) methods ${ }^{32,33}$. $1 \mathrm{~mL}$ of leaf and bark Murraya koenigii crude extracts at different concentration $(100,150,200,250$ and $300 \mu \mathrm{g} / \mathrm{mL})$ was mixed with $5 \mathrm{~mL}$ of $0.004 \%(\mathrm{v} / \mathrm{v}) \mathrm{DPPH}$ and finally the extracts were dissolved in methanol. The above procedures were repeated with BHT using ascorbic acid and $\alpha$-tocopherol as positive controls and the absorbance of the samples were measured at $517 \mathrm{~nm}$. Experiments were carried out in triplicate. The DPPH radical scavenging assay was calculated according to the formula.

Scavenging activity $(\%)=\left(\mathrm{A}_{0}-\mathrm{A}_{1}\right) / \mathrm{A}_{0} \times 100$ where $\mathrm{A}_{0}$-negative control (absorbance of solution with no samples); $A_{1}$ - positive control (absorbance of solution with samples).

Ferric-reducing antioxidant power assay: The ferric reducing properties of Murraya koenigii extracts were determined using the assay described by Yen and Chen ${ }^{34} .1 \mathrm{~mL}$ of leaf and bark extract (aqueous, methanolic, chloroform and $n$-hexane) was mixed with $2.5 \mathrm{~mL}$ of potassium phosphate buffer (0.2 M, pH 6.6) and $1 \mathrm{~g} / 100 \mathrm{~mL}$ potassium ferricyanide. The mixture was incubated at $50{ }^{\circ} \mathrm{C}$ for $20 \mathrm{~min}$ followed by trichloro acetic acid $(10 \%)$ addition to stop the reaction and finally equal volume of distilled water followed by $0.5 \mathrm{~mL}$ ferric chloride $(0.1 \mathrm{~g} / 100 \mathrm{~mL})$ was added and incubated at room temperature for $30 \mathrm{~min}$, absorbance was measured at $700 \mathrm{~nm}$. The whole experiment was carried out in triplicate. The above procedures were repeated with BHT using ascorbic acid and tocopherol as positive controls. The percentage of antioxidant activity in FRAP assay of the samples was calculated according to the formula.

Antioxidant activity $(\%)=\left(\mathrm{A}_{1}-\mathrm{A}_{0}\right) / \mathrm{A}_{1} \times 100$

where $\mathrm{A}_{0}$-negative control (absorbance of the control reaction); $A_{1}$ positive control (Absorbance in the sample).

Statistical analysis: All the results were expressed as mean \pm SD. The results were analyzed for statistical significance by one way analysis of variance (ANOVA) and Dunnet's $t$-test. At $95 \%$ confidence interval $p$ values less than 0.05 were considered to be significant.

\section{RESULTS AND DISCUSSION}

Streptozotocin induced diabetes in rodent's results in development of nephropathy similar to early stage clinical diabetic nephropathy ${ }^{35,36}$. The present experiment was conducted to study the antidiabetic activity of Murraya koenigii in rats to provide scientific evidence for its traditional usage in the control of diabetes. Although different polarity of leaf and bark extracts revealed more or less recovery of loss body weight butremarkable loss bw retrieval $(+14.37 \mathrm{~g})$ was demonstrated by aqueous leaf extracts, possibly due to strong glycemic control offered by the treatment. Changes in initial and final body weight of normal control and experimental groups are shown in (Table-1). Remarkable body weight loss was observed in diabetic controls and the data obtained from this study demonstrated that the different polarity of leaf and bark extracts of Murraya koenigii protects the diabetic rats from 


\begin{tabular}{|c|c|c|c|c|c|c|c|}
\hline \multirow{3}{*}{ Groups ( $\mathrm{n}=6$ ) } & \multicolumn{6}{|c|}{$\begin{array}{c}\text { TABLE-2 } \\
\text { EFFECT OF DIFFERENT POLARITY OF LEAVES AND BARK EXTRACTS OF } \\
\text { MURRYA KOENGII ON BLOOD GLUCOSE LEVEL IN NORMAL HEALTHY RATS }\end{array}$} & \multirow{3}{*}{ F-value } \\
\hline & \multirow{2}{*}{ Dose $(\mathrm{mg} / \mathrm{kg})$} & \multicolumn{5}{|c|}{ Blood glucose level (mg/dl) } & \\
\hline & & $0 \mathrm{~h}$ & $1 \mathrm{~h}$ & $2 \mathrm{~h}$ & $4 \mathrm{~h}$ & $8 \mathrm{~h}$ & \\
\hline Control & $2 \mathrm{~mL} / \mathrm{kg}$ & $91.46 \pm 3.59$ & $90.66 \pm 2.57$ & $92.5 \pm 4.53$ & $89.66 \pm 2.72$ & $91.5 \pm 4.66$ & 8.98 \\
\hline Glibenclamide & 10 & $87.33 \pm 4.26^{*}$ & $82.83 \pm 3.7^{*}$ & $78 \pm 3.51 *$ & $74.33 \pm 3.8^{*}$ & $87.66 \pm 3.65^{*}$ & $13.58 *$ \\
\hline MKL (Aqueous) & 300 & $83.63 \pm 4.26^{*}$ & $81.33 \pm 3.88^{*}$ & $81.56 \pm 3.13^{*}$ & $82.24 \pm 4.10 *$ & $83.33 \pm 3.63^{*}$ & 0.72 \\
\hline MKL (methanol) & 300 & $88.16 \pm 5.83$ & $81.83 \pm 5.10$ & $83.83 \pm 5.48$ & $87.33 \pm 6.11$ & $88.83 \pm 3.17$ & 0.58 \\
\hline MKL (Chloroform) & 300 & $89.83 \pm 4.48$ & $80.16 \pm 3.47$ & $82.83 \pm 3.30$ & $84.66 \pm 1.62$ & $87.83 \pm 3.64$ & 0.26 \\
\hline MKL ( $n$-hexane) & 300 & $88.87 \pm 2.78$ & $78.96 \pm 2.87$ & $82.89 \pm 2.67$ & $83.87 \pm 2.87$ & $85.76 \pm 2.98$ & 0.89 \\
\hline MKB (Aqueous) & 300 & $87.65 \pm 2.45$ & $79.67 \pm 2.22$ & $82.12 \pm 3.41$ & $84.78 \pm 1.12$ & $86.99 \pm 1.12$ & 0.76 \\
\hline MKB (Methanol) & 300 & $89.56 \pm 3.65$ & $78.43 \pm 2.11$ & $80.21 \pm 1.92$ & $85.12 \pm 1.21$ & $87.12 \pm 1.21$ & 0.79 \\
\hline MKB (Chloroform) & 300 & $85.78 \pm 2.65$ & $76.43 \pm 2.11$ & $82.43 \pm 2.18$ & $81.11 \pm 2.11$ & $86.32 \pm 1.21$ & 0.97 \\
\hline MKB (n-hexane) & 300 & $89.11 \pm 2.99$ & $78.65 \pm 4.31$ & $79.12 \pm 3.11$ & $82.12 \pm 1.22$ & $87.99 \pm 1.11$ & 0.98 \\
\hline
\end{tabular}

\begin{tabular}{|c|c|c|c|c|c|c|}
\hline \multirow{3}{*}{ Group $(n=6)$} & \multicolumn{5}{|c|}{$\begin{array}{l}\text { TABLE-3 } \\
\text { EFFECT OF DIFFERENT POLARITY LEAVES AND BARK EXTRACTS OF MURRYA KOENGII } \\
\text { ON BLOOD GLUCOSE LEVEL IN GLUCOSE LOADED HEALTHY WISTAR RATS }\end{array}$} & \\
\hline & \multirow{2}{*}{ Dose $(\mathrm{mg} / \mathrm{kg})$} & \multicolumn{5}{|c|}{ Blood glucose level $(\mathrm{mg} / \mathrm{kg})$} \\
\hline & & Basal value & $30 \mathrm{~min}$ & $60 \min$ & $90 \mathrm{~min}$ & $120 \min$ \\
\hline Control & $2 \mathrm{~mL} / \mathrm{kg}$ & $86.67 \pm 2.34$ & $138.35 \pm 1.23$ & $147.32 \pm 1.23$ & $141.21 \pm 2.98$ & $89.23 \pm 2.32$ \\
\hline Glibenclamide & 10 & $89.16 \pm 2.67 *$ & $121.83 \pm 2.34^{*}$ & $103.32 \pm 1.43 *$ & $92.21 \pm 2.76^{*}$ & $88.21 \pm 1.23^{*}$ \\
\hline MKL (Aqueous) & 300 & $89.87 \pm 3.21^{*}$ & $152.35 \pm 2.32 *$ & $158.32 \pm 2.34 *$ & $130.21 \pm 2.87 *$ & $88.21 \pm 2.21 *$ \\
\hline MKL (Methanol) & 300 & $91.76 \pm 2.13^{*}$ & $140.54 \pm 2.67 *$ & $130.12 \pm 2.11^{*}$ & $115.32 \pm 2.13^{*}$ & $94.12 \pm 1.29^{*}$ \\
\hline MKL (Chloroform) & 300 & $92.12 \pm 3.21$ & $131.65 \pm 2.54$ & $112.34 \pm 2.17$ & $98.21 \pm 2.12$ & $98.33 \pm 2.76$ \\
\hline MKL (n-hexane) & 300 & $91.78 \pm 2.56$ & $143.89 \pm 2.67$ & $118.87 \pm 3.87$ & $99.67 \pm 3.87$ & $99.76 \pm 3.98$ \\
\hline MKB (Aqueous) & 300 & $89.32 \pm 1.56$ & $140.12 \pm 2.12$ & $122.32 \pm 1.32$ & $108.12 \pm 1.11$ & $97.32 \pm 1.33$ \\
\hline MKB (Methanol) & 300 & $90.78 \pm 1.62$ & $141.23 \pm 1.21$ & $125.21 \pm 2.11$ & $101.21 \pm 3.11$ & $99.43 \pm 2.11$ \\
\hline MKB (Chloroform) & 300 & $88.78 \pm 1.21$ & $140.43 \pm 2.11$ & $129.12 \pm 1.12$ & $119.13 \pm 2.11$ & $99.65 \pm 4.11$ \\
\hline MKB (n-hexane) & 300 & $89.54 \pm 3.21$ & $141.43 \pm 2.11$ & $131.21 \pm 1.21$ & $108.12 \pm 131$ & $102.43 \pm 2.55$ \\
\hline
\end{tabular}

massive body weight loss, when given orally, daily for 10 days. Glibenclamide treated diabetic rats demonstrated a significant recovery in final body weight which was close to that of normal control rats. The rise in body weight (bw) was far less in the poorly controlled diabetic rats as compared to well-controlled diabetic rats This is in agreement with earlier studies on diabetic rats $^{37}$. Moreover, the weight gain was lesser in the diabetic rats when compared to normal control rats. Thus, the body loss due to catabolic effects seen in diabetic rats was only partially attenuated by the plant extracts.

A total of eight Murrya koengii leaf and bark extract viz., aqueous, methanolic, chloroform and $n$-hexane were examined on normal healthy, glucose loaded and streptozotocin-induced diabetes rats. The perusal of the results of anti-diabetic screening of Murrya koengii aqueous, methanolic, chloroform and $n$ hexane leaf and bark extracts on normal healthy rats is shown in (Table-2). This result clearly indicates that the extracts have no effect on normoglycemic animals but have significant role in reducing the elevated blood glucose level, which implies it acts through the extra pancreatic pathways rather than stimulating insulin secretion and results in anti-hyperglycaemic effect without affecting normal blood glucose level, which may be beneficial in case of mis-dosing.

The total phenolic content of different polarity like $n$ hexane, chloroform, methanol and water of leaf extracts of Murrya koengii are $1.3 \pm 1.23,2.2 \pm 2.12,3.3 \pm 2.98,5.7 \pm$
1.34 respectively. Aqueous, methanolic, chloroform and $n$ hexane leaf extracts were comparatively more effective in the Oral glucose tolerance test then bark. There was a significance reduction in blood glucose level observed at the dose levels of $300 \mathrm{mg} / \mathrm{kg}$ of the leaf extracts as compared to bark and other glucose-loaded control, which showed impaired glucose tolerance. Blood glucose level reached a peak of $158.32 \mathrm{mg} / \mathrm{dl}$ at $1 \mathrm{~h}$ after oral glucose loading in Murrya koengii aqueous leaf extracts in compared with control rats. The aqueous, methanolic, chloroform and $n$-hexane leaf extracts of Murrya koengii at the dose of $300 \mathrm{mg} / \mathrm{kg}$ produced a significant decrease of blood glucose level then bark extracts at 60, 90 and $120 \mathrm{~min} .(\mathrm{p}<0.01)$ after glucose loading and the effect persisted until $120 \mathrm{~min}$ (Table-3).

From the results obtained, it is clear that chronic administration of Murrya koengii leaf and bark extract to streptozotocininduced diabetes rats demonstrated blood glucose reduction in a constant dose but exposure time dependent manner. In streptozotocin-induced diabetic rats, among all the leaf and bark extracts of Murrya koengii the aqueous leaf at the dose level of $300 \mathrm{mg} / \mathrm{kg}$ revealed the significant highest reduction $(64.16 \%)$ followed by methanolic leaf extract $(60.86 \%)$ in fasting blood glucose level when compared to diabetic control group at the end of 10 days experimental period, whereas the chloroform, $n$-hexane leaf extract and aquous, methanolic, chloroform, $n$-hexane bark extract at the same dose revealed 


\begin{tabular}{|c|c|c|c|c|c|c|c|}
\hline \multirow{3}{*}{ Group $(n=6)$} & \multicolumn{6}{|c|}{$\begin{array}{c}\text { TABLE-4 } \\
\text { EFFECT OF DIFFERENT POLARITY LEAVES AND BARK EXTRACTS OF } \\
\text { MURRYA KOENGIION BLOOD GLUCOSE LEVEL ON HYPERGLYCAEMIC RATS }\end{array}$} & \multirow{3}{*}{ F-value } \\
\hline & \multirow{2}{*}{$\begin{array}{c}\text { Dose } \\
(\mathrm{mg} / \mathrm{kg})\end{array}$} & \multicolumn{5}{|c|}{ Blood glucose level (mg/dl) } & \\
\hline & & $0 \mathrm{~h}$ & $8 \mathrm{~h}$ & $16 \mathrm{~h}$ & $24 \mathrm{~h}$ & 10th day & \\
\hline Control & $2 \mathrm{~mL} / \mathrm{kg}$ & $251.46 \pm 3.51$ & $250.66 \pm 2.72$ & $250.5 \pm 4.53$ & $149.66 \pm 2.72$ & $251.5 \pm 4.66$ & 0.55 \\
\hline Glibenclamide & 10 & $247.33 \pm 4.2 *$ & $182.83 \pm 3.72 *$ & $148.5 \pm 3.1^{*}$ & $104.33 \pm 3.8^{*}$ & $97.66 \pm 3.5^{*}$ & $13.58^{*}$ \\
\hline MKL (Aqueous) & 300 & $249.44 \pm 3.21 *$ & $183.44 \pm 3.41 *$ & $141.43 \pm 2.4^{*}$ & $108.43 \pm 2.5^{*}$ & $89.42 \pm 1.5^{*}$ & $9.33 *$ \\
\hline MKL (Methanol) & 300 & $248.31 \pm 2.21 *$ & $190.32 \pm 1.52 *$ & $137.34 \pm 2.33^{*}$ & $107.34 \pm 3.22 *$ & $97.21 \pm 2.41 *$ & $12.49 *$ \\
\hline MKL (Chloroform) & 300 & $235.32 \pm 4.43$ & $201.21 \pm 3.23$ & $168.21 \pm 2.23$ & $121.11 \pm 1.26$ & $97.23 \pm 1.19$ & 7.43 \\
\hline MKL (n-hexane) & 300 & $230.87 \pm 2.34$ & $199.56 \pm 2.78$ & $161.89 \pm 2.56$ & $116.45 \pm 3.98$ & $99.65 \pm 3.56$ & 7.98 \\
\hline MKB (Aqueous) & 300 & $252.12 \pm 1.21$ & $200.12 \pm 1.34$ & $180.21 \pm 2.45$ & $163.32 \pm 3.21$ & $130.32 \pm 3.21$ & 9.87 \\
\hline MKB (Methanol) & 300 & $249.87 \pm 2.51$ & $220.87 \pm 1.54$ & $200.43 \pm 1.22$ & $178.32 \pm 1.21$ & $143.32 \pm 1.45$ & 7.98 \\
\hline MKB (Chloroform) & 300 & $256.98 \pm 1.65$ & $229.32 \pm 1.13$ & $190.56 \pm 1.89$ & $179.65 \pm 1.32$ & $153.23 \pm 2.11$ & 5.65 \\
\hline MKB (n-hexane) & 300 & $250.65 \pm 1.32$ & $220.89 \pm 1.65$ & $200.65 \pm 1.43$ & $180.21 \pm 1.23$ & $155.78 \pm 1.87$ & 6.43 \\
\hline
\end{tabular}

$58.69,56.85,48.32,42.65,40.38$ and $37.85 \%$ reduction on the same day respectively (Table-4 and Fig. 1). It indicates that the plant extracts exhibited similar effect as that of the standard drug, Glibenclamide (67.25\%). To determine whether there was a statistically significant difference in hypoglycemia achieved by the different time intervals chronically administered, the data were compared by using one-way analysis of variance and the individual groups were compared with control group using Dunnet's $t$-test.

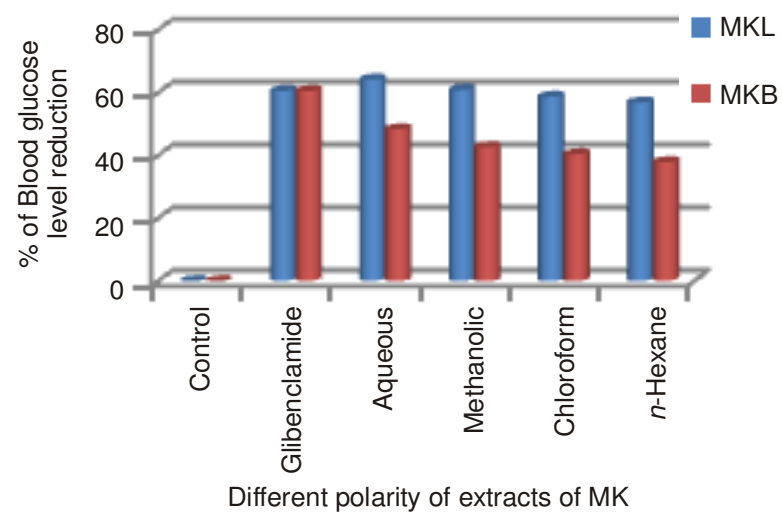

Fig. 1. Anti-diabetic activity of leaf and bark extracts of Murraya koenigii on streptozotocin induced diabetic rats, MKL: Murrya koengii leaf, MKB: Murrya koengii bark

Water is generally used in traditional settings to prepare the plant decoctions for health remedies. Many natural products including pigments, enzymes and bioactive components are soluble in water, which explains the highest yield of extract ${ }^{38}$. Hypoglycemic effect of Murrya koengii was also reported by some researchers ${ }^{39-41}$. The events like potentiation of pancreatic secretion of insulin from existing $\beta$ cells of Islets of Langerhans or to the extra pancreatic mechanism such as increased peripheral utilization of glucose through different enzymatic pathways may be attributed by the action of anti-hyperglycemic effect.

The mode of action could be either due to increased glycogenesis or decreased glycogenolysis or gluconeogenesis ${ }^{39}$ and/or due to insulin secretogogue effect of Murraya koenigii, which causes an increased glucose uptake and its utilization by cells ${ }^{41}$. The results obtained in this study are in good agree- ment with those observed by previous investigators in alloxaninduced diabetic rats ${ }^{28,42,43}$. According to Rerup et al ${ }^{44}$ streptozotocin, $\beta$-cytotoxin induces diabetes inducing agent in a wide variety of animal species through a massive destruction of $\beta$-cells of the islets of Langerhans and resulting in reduced synthesis and release of insulin. Sulphonylureas produce hypoglycaemia by increasing the secretion of insulin from pancreas and by increasing the glycogen deposition in the liver was reported $^{45,46}$, Murraya koenigii leaves contain different vital components like alanine, lysine, carbohydrates, iron, calcium, niacin and volatile oils was reported ${ }^{47}$. The increased insulin secretion in diabetic could be due to presence of alanine, leucine ${ }^{48}$, carbohydrate, niacin, iron and calcium in aqueous extract ${ }^{49,50}$ and the various constituents in the volatile oil (indole alkaloids such as mahanine and mahanimbine, sesquiterpene such as cadinene and monoterpene such as dipentene $)^{51}$ in methanol extract of Murraya koenigii. Streptozotocin-treated animal's receiving the leaf extract of Murrya koengii demonstrated rapid normalization of blood glucose levels in comparison to control and this could be due to the possibility that some ' $\beta$ cells' were still active and were acted upon by Murrya koengii to extract their insulin releasing effect and clearly indicate that the action of Murrya koengii is probably mediated by an enhanced secretion of insulin. The increase in plasma insulin concentration could also be due to the longer lasting stimulant effect on $\beta$-cells of pancreatic islets or due to pancreatic $\beta$-cells regeneration of Murraya koenigii ${ }^{41}$.

The effect of aquous, methanolic, chorofrom and $n$-hexane leaf and bark extractsof Murraya koenigii on both DPPH scavenging assay and FRPA assay in streptozotocin induced diabetis rats is shown in (Table-5). The aqueous leaf extracts of Murraya koenigii demonstrated highest DPPH free radical scavenging value (89.32) and FRPA value (76.32) than the other extracts of leaf and bark in both DPPH and FRAP.

The present study reveals that the medicinal (aqueous leaf extract) effect of this plant was also found to be much comparable to that of the standard drug glibenclamide, treated rats. It may be concluded that the aqueous leaf extract of Murraya koenigii at the dose $(300 \mathrm{mg} / \mathrm{kg})$ has more potent antihyperglycaemic activity than the other extracts of leaf and bark in streptozotocin induced diabetic rats and was also found to be similar effect to that of the standard drug glibenclamide. In 
DIFFERENT POLARITY OF LEAVE AND BARK EXTRACTS OF MURRYA KOENGII ARE USED IN BOTH DPPH SCAVENGING ASSAY AND FRPA ASSAY

\begin{tabular}{|c|c|c|c|c|}
\hline Extracts & DPPH scavenging assay & F-values & FRPA assay & F-values \\
\hline MKL (Aqueous) & $89.32 \pm 1.65^{*}$ & $0.98 *$ & $76.32 \pm 1.87 *$ & $0.87 *$ \\
\hline MKL (Methanol) & $76.34 \pm 1.56^{*}$ & $0.88 *$ & $64.87 \pm 1.45^{*}$ & $0.65 *$ \\
\hline MKL (Chloroform) & $67.89 \pm 1.54$ & 0.78 & $51.98 \pm 1.89$ & 0.71 \\
\hline MKL (n-hexane) & $59.56 \pm 1.32$ & 0.65 & $39.98 \pm 1.67$ & 0.43 \\
\hline MKB (Aqueous) & $58.98 \pm 1.11$ & 0.98 & $38.98 \pm 1.23$ & 0.68 \\
\hline MKB (Methanol) & $56.87 \pm 1.12$ & 0.87 & $35.54 \pm 3.21$ & 0.67 \\
\hline MKB (Chloroform) & $48.98 \pm 2.32$ & 0.87 & $31.98 \pm 131$ & 0.83 \\
\hline MKB (n-hexane) & $44.76 \pm 1.11$ & 0.88 & $28.67 \pm 8.21$ & 0.85 \\
\hline
\end{tabular}

conclusion, the extract of Murrya koengii leave confirms the role in the treatment of diabetes mellitus and can form a part of therapy in its management. Further studies are warranted to determine the detailed anti-diabetic principles and mechanistic elucidation of the leaf.

\section{REFERENCES}

1. S. Yadav, V. Vats, Y. Dhunnoo and J.K. Grover, J. Ethnopharmacol., 82 111 (2002).

2. H. King, R.E. Aubert and W.H. Herman, Diabetes Care, 21, 1414 (1998).

3. J.P. Boyle, A.A. Honeycutt, K.M. Narayan, T.J. Hoerger, L.S. Geiss, H. Chen and T.J. Thompson, Diabetes Care, 24, 1936 (2001).

4. G. Sumana and S.A. Suryawashi, Indian J. Exp. Biol., 39, 748 (2001).

5. S. Berger, Horm. Metab. Res., 17, 111 (1985).

6. R. Hupponen, Med. Toxicol., 2, 190 (1978).

7. World Helth Organization, Second Report of the WHO Expert Committee on Diabetes Millitus, Technical Report Series (1980).

8. V. Upadhaya and K. Pandey, in ed.: J.S. Bajaj, Ayurvedic Approach to Diabetes Mellitus and its Management by Indigenous Resurces, Diabetes Millitusin Developing Countries, Interprint, New Delhi, pp. 375-37 (1984).

9. B.N.R. Burshra and D.T. Ganga, Asian J. Microbial. Biotechnol. Environ. Exp. Sci., 5, 319 (2003).

10. A.K. Twari and M. Rao, Curr. Sci., 83, 30 (2002)

11. C.C. Lin, Am. J. Clin. Med., 20, 296 (1992).

12. A. Ziyyat, A. Legssyar and H. Mekhfi, J. Ethnopharmacol., 58, 45 (1997).

13. G.V. Satyavati, A.K. Gupta and N. Tandon, Medicinal Plants of India. (Indian Council of Medical Research, New Delhi, vol. 2 (1987).

14. F. Brinker, Herb Contraindications and Drug Interactions, Electic Medical Publications, Sandy, USA, edn. 2, pp. 36-82 (1998).

15. M.T. Pepato, A.M. Baviera, R.C. Vendramini, M.P.M.S. Perez, I.C Ketelhut and I.L. Brunetti, Biotechnol. Appl. Biochem., 37, 15 (2003).

16. N. Tomok, A. Takshi, T. Hiromu, I. Yuka, M. Hiroko and I. Munekazu, J. Health Sci., 48, 273 (2002).

17. A.M. Udayakumar, A.V. Pathare, D. Dennison and J.A. Raeburn, J. Appl. Genet., 50, 73 (2009).

18. G. Ghosh, D.M. Kar, B.B. Subudhi and S.K. Mishra, Der Pham. Lett., 2, 206 (2010).

19. S.M. Wazir, S. Saima, A.A. Dasti and M. Subhan, Pak. J. Plant. Sci., 13, 29 (2007).

20. S. Jena, S.K. Mishra, G. Ghosh and P.K. Chand, Indian Drugs, 48, 27 (2011).

21. F.M. Akhtar and M.R. Ali, J. Pak. Med. Assoc., 34, 239 (1984).

22. D.M. Eisenberg, R.C. Kessler, C. Foster, F.E. Norlock, D.R. Calkins and T.L. Delbanco, N. Engl. J. Med., 328, 246 (1993).

23. A.H. MacLennan, D.H. Wilson and A.W. Taylor, The Lancet, 347, 569 (1996).
24. P. Carter, L.J. Gray, J. Troughton, K. Khunti and M.J. Davies, BMJ, 341, c4229 (2010)

25. P.Arulselvan, K.G.P. Senthil, K.D. Sathish and S. Subramanian, Pharmazie, 61, 874 (2006).

26. P. Arulselvan and S.P. Subramanian, Chem. Biol. Interact., 165, 155 (2007).

27. M.P. Goutam and R.M. Purohit, Indian J. Pharm., 36, 11 (1974).

28. K. Vinuthan, K.V. Girish, J.P. Ravindra, Jayprakash and K. Narayan, Indian J. Physiol. Pharmacol., 48, 348 (2004).

29. L.C. Miller and M.L. Tainter, Proc. Soc. Exp. Bio. Med., 57, 261 (1944).

30. A.R. Muhammad, J. Ayub. Med. Coll. Abbottabad, 21, 184 (2009).

31. H. Al-A. Abdulelah, M.N. Zurainee, M. Al-M. Hesham and M. Rohela, Molecules, 15, 8366 (2010).

32. M. Burits and F. Bucar, Phototherapy Res., 14, 323 (2000).

33. M. Cuendet, K. Hostettmann and O. Potterat, Helv. Chim. Acta, 80, 1144 (1997).

34. G.C. Yen and H.Y. Chen, J. Agric. Food Chem., 43, 27 (1995).

35. R. Rasch and C.E. Mogensen, Acta Endocrinol., 95, 376 (1980).

36. C. Sassy-Prigent, D. Heudes, S. Jouquey, D. Auberval, M.F. Belair, O. Michel, G. Hamon, J. Bariéty and P. Bruneval, Lab. Invest., 73, 64 (1995).

37. R. Reasch, Diabetologia, 18, 413 (1980).

38. M.C. Majorie, Clin. Microbial. Rev., 12, 564 (1999).

39. A.B. Khan, A. Abraham and S. Leelamma, Indian J. Biochem. Biophys., 32, 106 (1995).

40. S.S. Bhat, The Antidiabetic Activity of Murrayakoenigii Spreng and the Hyperglycemic Activity of Leucasasperaspreng, M.V. Sci. Thesis Submitted to UAS, Bangalore, India (1995).

41. A.R. Rupashree, The Effect of Extracts of Murrayakoenigii Spreng on Blood Glucose Concentration in Diabetic Animal Model, M.V. Sci. Thesis Submitted to UAS, Bangalore, India (1999).

42. M.A. Chude, O.J. Orisakwe, K.S. Gamaniel, O.H. Vongtau and E. Obi, Indian J. Pharmacol., 33, 215 (2001).

43. L. Pari and M.A. Satheesh, J. Ethnopharmacol., 91, 109 (2004).

44. C.C. Repu, Pharmacol. Rev., 22, 485 (1970).

45. G.M. Grodsky, G.H. Epstein, R. Fanska and J.H. Karam, Fedproc., 36, 2719 (1971).

46. R.S. Yellow, H. Black, M. Vilazan and S.A. Berson, Diabetes, 9, 356 (1960).

47. J.S. Pruthi and S. Condiment, National Book Trust, Green Park, J.K., Jama Masjid, New Delhi, Offset Printers, pp. 108-111 (1979).

48. R.M. Berne and M.N. Levy, Physiology., 2nd ed. The C. V. Mosby Company, Westline Industrial Drive, St. Louis, Missouri (1988).

49. R.K. Murray, D.K. Granner, A. Mayes and V.W. Rodwell, Harper's Biochemistry, 24 ${ }^{\text {th }}$ ed. Prentice-Hall International Inc, USA (1996).

50. U. Satyanarayana, in: ed.: A. Sen, Biotechnology, Metabolism in Biochemistry, Books and Allied (P) Ltd, Calcutta, edn 1, pp. 247-449. (1999).

51. N. Tommasi, S.F. De, G. Cirino, C. Cicala and C. Pizza, Planta Medica, 57, 414 (1991). 